\title{
¿Es insuficiente la disposición interpretativa del caso fortuito o fuerza mayor como causal de terminación del contrato de trabajo en la Ley Orgánica de Apoyo Humanitario? Un análisis desde el Derecho comparado con ocasión del Covid-19
}

¿Is the interpretative provision for fortuitous event or force majeure insufficient regarding the termination of the employment contract in the Organic Law of Humanitarian Support? An analysis from Comparative Law on the occasion of Covid-19

Gabriel Eduardo Almeida Vintimilla*

Recibido / Received: 7/10/2020

Aceptado / Accepted: 30/03/2021

DOI: https://doi.org/10.18272/ulr.v8i1.2024

Citación:

Almeida Vintimilla, G.E. «Es insuficiente la disposición interpretativa del caso fortuito o fuerza mayor como causal de terminación del contrato de trabajo en la Ley Orgánica de Apoyo Humanitario? Un análisis desde el Derecho comparado con ocasión del Covid-19». USFQ Law Review, Vol 8, no 1, mayo de 2021, pp. 1 - 25, doi: 10.18272/ulr.v8i1.2024

Abogado por la Universidad San Francisco de Quito USFQ, casilla postal 17-1200-841, Quito 170901, Pichincha, Ecuador. Correo electrónico: gabriel.almeida2695@gmail.com ORCID iD: https://orcid.org/0000-0002-6561-6135 


\section{RESUMEN}

Dentro de las varias medidas emergentes emitidas en el Ecuador a partir de la declaratoria del Covid-19 como pandemia, consta la disposición interpretativa a la causal de fuerza mayor o caso fortuito, para la terminación de los contratos individuales de trabajo; con la reciente entrada en vigencia de la Ley Orgánica de Apoyo Humanitario (en adelante LOAH). La disposición interpretativa consiste en establecer un único parámetro de aplicación de dicha causal, relativo a una situación de imposibilidad absoluta o cese definitivo de la actividad productiva del empleador. El presente artículo busca identificar los principales presupuestos fácticos y jurídicos que dicha disposición ha ignorado y que, por otro lado, han sido considerados y desarrollados en el Derecho Iberoamericano Comparado que -por esencia- deberían también serle inherentes. De igual manera, el presente artículo pretende exponer las limitaciones y falencias normativas existentes en el sistema laboral ecuatoriano, tanto en lo subjetivo como en lo procedimental de la norma, cuestión que tampoco ha sido suficientemente solucionada por dicho cuerpo normativo. Finalmente, se expondrá la necesidad de incorporar la teoría de la responsabilidad civil subjetiva y objetiva, respecto a la imputabilidad del empleador en la ecuación determinativa de la causal en referencia. Todo lo cual resulta aún más necesario por el creciente número de terminaciones contractuales y despidos, en medio de una situación crítica como la actual pandemia.

\section{Palabras clave}

Caso fortuito; fuerza mayor; derecho laboral; LOAH, derecho iberoamericano; invocación injustificada; imputabilidad empleador; responsabilidad laboral.

\section{Abstract}

Within the several emerging measures issued in Ecuador, since the declaration of Covid-19 as a worldwide pandemic, there is an interpretative provision rule for fortuitous event and force majeure, in order to regulate its application regarding the termination of individual employment contracts, according to the recent entry into force of the Organic Law of Humanitarian Support. The interpretative provision establishes a single application parameter for this causal, based on a situation of absolute impossibility or definitive cessation of the productive activity of the employer. This article seeks to identify the main factual and legal assumptions that this provision has ignored, in comparison with those that have indeed been considered and developed in Ibero-American Comparative Law; assumptions that in essence, should also be inherent to said provision. At the same time, this article pretends to expose the limitations and normative flaws existing in the Ecuadorian labor system, both subjective and procedural in the norm. which in conclusion will demonstrate that all the normative and regulatory shortcomings have not been sufficiently solved by said Humanitarian Support Law. Finally, this article will 
attempt to demonstrate the need to incorporate the theories of subjective and objective civil liability, regarding the imputability of the employer in the determinative equation of the factual and legal assumptions of the causal in reference. All of which, becomes even more necessary, due to the increasing number of contractual terminations and dismissals, in the midst of a critical situation such as the current pandemic.

\section{KEYWORDS}

Fortuitous event; force majeure; labor matters; cause for termination of employment contract; Ecuadorian Organic Law of Humanitarian Support; Ibero-American Comparative Law

\section{INTRODUCCIÓN}

El Código de Trabajo ecuatoriano (en adelante CT), determina, en el numeral 6 de su artículo $169^{1}$ al caso fortuito o fuerza mayor como una causal de terminación de la relación laboral por eventos específicos como: incendios, terremotos, tempestades, explosiones, plagas de campo y guerra; o a modo general, por cualquier otro acontecimiento extraordinario que las partes contratantes no pudieron prever o que previsto, no lo pudieron evitar. ${ }^{2}$ Por otro lado, el Código Civil ecuatoriano (en adelante CC), en su artículo $30^{3}$, determina a la fuerza mayor y el caso fortuito como aquel evento imprevisto que no es posible resistir y prescribe algunos ejemplos adicionales como: un naufragio, un terremoto, el apresamiento de enemigos, los actos de autoridad ejercidos por un funcionario público, etc.

Tanto la jurisprudencia nacional como la doctrina han desarrollado los elementos que componen al caso fortuito y la fuerza mayor. En primer lugar, está la imprevisibilidad, misma que alude a la idoneidad del agente para anticipar los efectos de un suceso dañoso que impide o impedirá el cumplimiento de la obligación contractual. Por lo tanto, una situación imprevisible tendrá lugar cuando la posibilidad de su accionante supera la aptitud moral y previsión que se debe exigir al deudor de una obligación, que en el ámbito civil contractual es la del hombre común. ${ }^{4}$ Por otro lado, se contempla a la irresistibilidad. La jurisprudencia la determina como un hecho inevitable provocado por la insuficiencia material del individuo para obstaculizar o impedir la producción de un acontecimiento dañoso o lesivo, para lo cual se evaluarán las condiciones

1 Artículo 169 numeral 6, Código de Trabajo [CT], R.O. Suplemento 167 de 16 de diciembre de 2005, reformado por última vez R.O. Suplemento 229 de 22 de junio de 2020.

2 Jorge Vásquez López, Derecho Laboral Ecuatoriano (Quito: Editorial Colección Libertad, 2009), 202.

3 Artículo 30, Código Civil [CC], R.O. Suplemento 46 de 24 de junio de 2005, reformado por última vez R.O. Suplemento 96 de 8 de julio de 2019.

4 Causa No. 17321-2007-0264 (No. 462-1999 previo al resorteo de causas), Corte Nacional de Justicia (ex Corte Suprema de Justicia), Sala de lo Civil y Mercantil, 12 de noviembre de 2007, 3395. 
de idoneidad del agente, sus cualidades y posibilidades reales y posibles de impedir consecuencias dañosas. ${ }^{5}$ Por su parte, la jurisprudencia ecuatoriana en materia mercantil, ha destacado la importancia de añadir a los elementos referidos una característica de relatividad, con base en la cual dichos elementos deben estar revestidos.

En tal virtud, la imprevisibilidad y la irresistibilidad de un hecho dependen de las personas y muchas veces de su profesión, es decir, lo que es imprevisible para unos no lo será para otros que tienen mayores conocimientos de alguna ciencia o arte. Lo mismo podría decirse de la irresistibilidad, respecto de la posibilidad del agente para evitar un daño ya previsto, mediante medidas oportunas que no están al alcance de cualquier persona, pero sí de técnicos o entendidos en determinada materia o área de especialidad. ${ }^{6}$

Así, la jurisprudencia ha sido concordante en que, la unión copulativa y relativa de estos elementos, provocará la terminación de un contrato, siempre que produzca imposibilidad jurídica o física de ejecutar la prestación debida. ${ }^{7}$ Este criterio, propio del ámbito civil, parece ser el que se encuentra detrás del ideal que el legislador ecuatoriano ha pretendido incorporar en la LOAH para el tratamiento de la causal en estudio en el ámbito laboral.

En materia laboral, el desarrollo jurisprudencial de la causal en estudio ha sido un tanto escueto. Sin embargo, dentro de un caso relativo al de cierre de empresa, la Sala que lo conoció determinó que dicho evento no constituye fuerza mayor ni caso fortuito, pues el mismo resultó atribuible a la negligencia del empleador por haber incumplido previamente sus obligaciones fiscales. En dicho caso, la causal en referencia perdió todo sustento jurídico por verificarse la negligencia previa del empleador. ${ }^{8}$

Dentro de la normativa nacional de jerarquía infra legal, son destacables dos acuerdos ministeriales emitidos por el Ministerio de Trabajo que cobraron especial relevancia a partir de la declaratoria de estado de excepción en el territorio nacional por la emergencia sanitaria provocada por la pandemia del Covid-19. ${ }^{9}$ En primer lugar, el Acuerdo Ministerial No. MDT-2020-077 ${ }^{10}$ que tuvo por objeto preservar las fuentes de trabajo, evitar despidos y fomentar el acuerdo entre las partes, determinó algunas medidas emergentes a la jornada laboral tales como: reducción, modificación y suspensión. De igual manera, implementó el teletrabajo como modalidad alternativa cuando fuere

6 Corte Nacional de Justicia (ex Corte Suprema de Justicia), Primera Sala de lo Civil y Mercantil, 13 de diciembre de 2001, pág. 2273.

8 Corte Nacional de Justicia (ex Corte Suprema de Justicia), Tercera Sala de lo Laboral y Social, 29 de mayo de 2001, pág. 2533.

9 Decreto Presidencial No. 1017, Presidencia de la República [Por medio del cual se declara estado de excepción en el territorio nacional por el Covid-19], Registro Oficial Suplemento 163 de 17 de marzo de 2020.

10 Acuerdo Ministerial No. MDT-2020-077, Ministerio de Trabajo, 15 de marzo de 2020.
} 
posible realizarlo y se cuente con los medios efectivos para ello. En segundo lugar, el Acuerdo Ministerial No. MDT-2020-081, ${ }^{11}$ que, si bien tuvo por objeto la modificación del instructivo de cumplimiento de obligaciones por parte de los empleadores públicos y privados, fue el motivo fundamental para que la causal en estudio haya sido mayormente considerada y aplicada, en un panorama aún escueto de su desarrollo jurídico previo. En el artículo segundo de dicho acuerdo, se estableció lo siguiente:

[...] Art.2. - Agréguese la Disposición Transitoria Séptima. - Séptima: El empleador que alegue la terminación del contrato individual de trabajo de conformidad con la causal 6 del artículo 169 del Código de Trabajo, deberá dentro de las 24 horas posteriores a la mencionada terminación realizar lo siguiente:

1. Registrar en el Sistema Único de Trabajo (SUT); los fundamentos que sustenten la terminación del contrato individual de trabajo; la información registrada será responsabilidad exclusiva del empleador. Los empleadores que no realicen este registro, serán sancionados de conformidad con el artículo 7 del Mandato Constituyente 8 .

2. Notificar al trabajador, la terminación del contrato individual de trabajo por cualquier medio de notificación contemplado en las normativas legales vigentes.

En virtud de esta disposición, no existía para el empleador obligación alguna de obtener una autorización previa ni mucho menos una evaluación de los fundamentos de la causal en estudio por parte de la autoridad competente. Lo dicho llama la atención por cuanto atenta al objeto de dichos acuerdos y -fundamentalmente- a la efectiva configuración de esta causal, porque no se contempló ningún tipo de procedimiento de impugnación, al menos en sede administrativa.

Así, el Ecuador enfrentó una situación de incertidumbre jurídica en el ámbito laboral con respecto a la causal en estudio, en virtud de la pandemia. Debido a su carente desarrollo tanto en la legislación como en la jurisprudencia, se promulgó la Ley Orgánica de Apoyo Humanitario como una suerte de salvación jurídica. Dicha Ley combinó e incorporó lo establecido por los dos acuerdos ministeriales antes referidos, y estableció además que, la invocación injustificada de la causal en estudio por parte del empleador, configuraría un despido intempestivo cuya indemnización debe aumentarse en uno punto cinco $(1.5)^{12}$ a la prevista por el artículo 188 del CT.

Para complementar lo anterior, el legislador ecuatoriano determinó también la interpretación obligatoria para la aplicación de la causal en estudio. En virtud de esta disposición interpretativa, el numeral 6 del artículo 169 del CT debe interpretarse de la siguiente forma:

11 Acuerdo Ministerial No. MDT- 2020- 081, Ministerio de Trabajo, 10 de abril de 2020.

12 Artículo 17, Ley Orgánica de Apoyo Humanitario [LOAP], R.O. Suplemento 229 de 22 de junio de 2020. 
[...] En estos casos, la imposibilidad de realizar el trabajo por caso fortuito o fuerza mayor estará ligada al cese total o definitivo de la actividad económica del empleador, sea persona natural o jurídica. Esto quiere decir, que habrá imposibilidad cuando el trabajo no se pueda llevar a cabo tanto por los medios físicos habituales como por medios alternativos que permitan su ejecución, ni aún por medios telemáticos. ${ }^{13}$

El legislador ecuatoriano ha determinado la operatividad de esta causal a un solo parámetro de aplicación; es decir, solamente si estos efectos producen imposibilidad absoluta de realizar el trabajo, lo cual se traduce únicamente en la imposibilidad jurídica de ejecución de una obligación, limitando el espacio interpretativo de la causal, ignorando también la inclusión de una serie de elementos y características recogidas en las legislaciones que serán analizadas a continuación, razón por la cual, lejos de ser una salvación jurídica podría representar más problemas que soluciones, pues solamente en el mes de junio del año 2020, el Ministerio de Trabajo ecuatoriano registró más de 17.000 denuncias por despido intempestivo, ${ }^{14}$ cantidad que tan solo en un mes se incrementó a casi $270.000 .{ }^{15}$

Evidentemente, el problema jurídico suscitado, tiene relación con la aplicabilidad y procedencia de la causal en estudio, así como su consecuente errónea interpretación e invocación. La carencia normativa evidenciada durante la pandemia, así como en el escueto desarrollo jurídico de dicha causal con anterioridad a ella, demuestran que a pesar de que las instituciones públicas han hecho sus mejores esfuerzos, la misma es aún insuficiente. Por lo tanto, el presente artículo tiene como primer objetivo determinar la procedencia del caso fortuito o fuerza mayor como causal de terminación de la relación laboral, a partir de un análisis crítico comparativo, tomando como punto de partida la normativa vigente en el Ecuador, en contraste con el Derecho Comparado Iberoamericano, por ser el más cercano a la realidad nacional. Como segundo punto, el presente artículo pretende lograr también que el lector encuentre un acercamiento mucho más amplio de la causal en estudio e igualmente le permita obtener una visión integral, a efectos de cuestionar los requisitos para su procedencia alejándolo de un único parámetro de análisis conforme ha establecido el legislador ecuatoriano. Finalmente, el tercer objetivo del presente artículo consistirá en demostrar la necesidad de integrar la teoría de la responsabilidad civil subjetiva, así como la teoría de la responsabilidad civil objetiva dentro de la ecuación determinativa de la causal en estudio. Ello, con

13 Disposición Interpretativa Primera, LOAP.

14 María Vanessa Silva, "173 000 trabajadores han sido desvinculados durante la emergencia sanitaria”. El Comercio, (12 de junio de 2020).https://www.elcomercio.com/actualidad/despidos-trabajadores-sanciones-emergencia.html.

15 "Desempleo: Casi 270000 contratos terminados durante la pandemia en Ecuador". El Universo, (29 de julio de 2020). https://www.eluniverso.com/noticias/2020/07/29/nota/7923219/desempleo-pandemia-coronavirus-ecuador-2020-contratos-terminados. 
el fin de verificar la relevancia que representará lo descrito para el problema jurídico laboral en el Ecuador, con base en un parámetro crítico comparativo de análisis en el marco del Derecho Comparado.

\section{El Caso fortuito y la Fuerza mayor como causal de TERMINACIÓN DEL CONTRATO INDIVIDUAL DE TRABAJO EN EL DERECHO CoMparado IbEROAMERICANo}

\subsection{CaRaCTERÍSTICAS, FUNCIONAMIENTO Y APLICABILIDAD DE LA CAUSAL EN ESTUDio EN EL DERECHO labORAL CHILENO Y SUS ELEMENTOS FUNDAMENTALES DESDE EL ÁMBITO JURÍDICO CIVIL}

De manera casi idéntica al sistema ecuatoriano, el artículo 45 del CC chileno ${ }^{16}$, trata como sinónimos al caso fortuito y a la fuerza mayor, y los determina como una serie de eventos externos, que no son exclusivos ni excluyentes, pero sí imprevistos e irresistibles, por los que civilmente el deudor de una obligación no es responsable, a menos que, conforme el artículo $1547^{17}$ de dicho cuerpo normativo determinado evento haya sobrevenido por su culpa.

Con ocasión del terremoto del año 2010, la Dirección del Trabajo de Chile estableció una directriz para la aplicación estricta de la causal en estudio. La Dirección determinó el cumplimiento copulativo de los siguientes requisitos: i) que los dańos provocados por el terremoto en las instalaciones de una empresa se deban unívoca, directa y causalmente a la ocurrencia del mismo; ii) que el empleador que invoque esta causal no haya podido haber contribuido al acaecimiento del mismo o de sus efectos dańosos; y iii), que el terremoto y sus efectos directos sean irresistibles, esto es, que suponga la nula posibilidad de mantener el puesto de trabajo de los trabajadores y por ende, el cumplimiento de las obligaciones contractuales de la parte empleadora. ${ }^{18}$

Por su parte, la jurisprudencia chilena es concordante en determinar que en la configuración de la causal en estudio, deben concurrir ciertos requisitos copulativos respecto del hecho invocado por el empleador para ponerle término al contrato de trabajo con su dependiente, añadiendo al análisis la ponderación de los factores específicos de la fisonomía de cada empresa para determinar en último término la imposibilidad de continuar la relación laboral. ${ }^{19}$

16 Artículo 45, Código Civil Chileno, Diario Oficial 30 de mayo de 2000, reformado por última vez el 24 de septiembre de 2009. http://www.oas.org/dil/esp/codigo_civil_chile.pdf.

17 Artículo 1547, Código Civil Chileno,2000.

18 Dictamen Ord. No. 1412/021, Dirección del Trabajo de Chile, Departamento Jurídico, Diario Oficial 19 de marzo de 2010. https://www.dt.gob.cl/legislacion/1624/w3-article-97663.html.

19 Caso Cea c. Medina, Rol No. 6008-201, Corte Suprema de Chile, 11 de abril de 2012, Base Jurisprudencial: www.pjud.cl. 
Para los autores Gamoral y Guidi, la causal en estudio se configura efectivamente siempre que se cumplan tres requisitos esenciales: i) imprevisibilidad, ii) irresistibilidad y, iii) que el hecho no haya sido provocado por quien lo alega. En este sentido, dichos autores determinan a la imprevisibilidad como la inexistencia racional de anticipar la ocurrencia de un determinado hecho. Respecto a la irresistibilidad, los autores mencionan que aquella tiene relevancia cuando quien lo sufre sea incapaz de evitar su ocurrencia. Agregan también que el caso fortuito o fuerza mayor deben producir una consecuencia de imposibilidad jurídica y física que excuse definitivamente a las partes contratantes del cumplimiento de las obligaciones principales del contrato de trabajo. ${ }^{20}$

Para Varas, la imprevisibilidad del hecho que provoca la terminación de la relación laboral existe cuando este ha sido imposible de anticipar, mencionando además que estos hechos deben ser inimputables, irresistibles y existir una relación de causalidad entre el hecho y el resultado. Para la autora, la irresistibilidad del hecho es el requisito más importante para la configuración de esta causal, pues sostiene que la relación con el hecho debe generar en el empleador una imposibilidad absoluta de cumplir con sus obligaciones. ${ }^{21}$ En cambio, Fernández ha sostenido que el primer requisito para la configuración de la causal en estudio es la imputabilidad del empleador; es decir, que las consecuencias de determinado hecho no se originen en su culpa, negligencia o dolo. ${ }^{22}$

Para este sector de la doctrina chilena, la configuración de la causal en estudio estaría completa cuando la ausencia de culpa o dolo del empleador en la imposibilidad de continuar cumpliendo sus obligaciones contractuales, quede demostrada. Dicho de otra forma, se trata en definitiva de un juicio de reproche a la conducta verificada o que debió verificar el empleador respecto del cumplimiento de sus obligaciones dentro del contrato de trabajo. ${ }^{23}$

Al igual que Fernández, Coustasse e Iturra consideran a la imputabilidad como el primero y más importante de los elementos de la causal en estudio. En materia laboral, los autores determinan que si el empleador es el obligado a otorgar el trabajo convenido a su empleado, podría fácilmente establecerse que es en esta obligación en la que debe realizarse el análisis o reproche de su imputabilidad. ${ }^{24}$

20 Sergio Gamoral Contreras y Caterina Guidi Mogia, Manual del Contrato de Trabajo (Santiago de Chile: Editorial LexisNexis Abeledo-Perrot, 2010), 112.

21 Karla Varas Marchant, “Qué pasa con los derechos de los trabajadores tras el terremoto?”, Revista Laboral Chilena, no. 186 (2010): 68

22 Juan José Fernández Domínguez, Expedientes de regulación de empleo (Madrid: Editorial Trotta S.A., 1993), 26. Ver: Juan Luis Castro Jara, "Caso fortuito o fuerza mayor como causal de término de la relación laboral. Requisitos del caso fortuito, ¿se confunden con la inimputabilidad del empleador?”, en Revista Chilena de Derecho del Trabajo y de la Seguridad Social No. 11 volumen VI (Santiago de Chile: 2015), 13-35.

23 Ibid.

24 Alberto Coustasse del C. y Fernando Iturra A., El caso fortuito ante el Derecho Civil (Santiago: Editorial Jurídica de Chile, 1958), 86. 
Por lo tanto, la culpa o negligencia del empleador, en el sistema chileno, consistirá para efectos de la configuración de la causal en estudio, en que el hecho externo imprevisible e irresistible no haya contado con una acción material suficiente por parte del empleador que demuestre haber agotado todos los medios o recursos a su alcance para evitar o aminorar su acaecimiento. En este sentido, frente a un hecho imprevisto o previsible pero potencialmente irresistible, no se ha hecho todo lo necesario para evitarlo. ${ }^{25}$

Coustasse e Iturra sostienen también que los elementos de inimputabilidad, imprevisibilidad e irresistibilidad de la causal, deben cumplir con tres requisitos adicionales para su configuración y análisis, a saber:

[...] 1) Relatividad, ya que se debe considerar el cumplimiento del deber del obligado de evitar la ocurrencia de determinado hecho, frente a un contexto real; 2) concreción, a efectos de que un determinado hecho sea considerado como imprevisible, será indispensable relacionarlo de forma objetiva con otras circunstancias de tal calidad, por ejemplo: el lugar geográfico donde ocurre el hecho, la época del ańo o tiempo donde tiene lugar, habitualidad, intensidad, etc. y; 3) dependencia, pues determinado hecho será imprevisto cuando a pesar de que se han tomado las precauciones para evitar el hecho o sus efectos dañosos, éste se produce igualmente, porque concurrieron otros factores que normalmente no concurrirían, y por lo mismo se determinaría una imposibilidad de precaverlos. ${ }^{26}$

El anterior es un criterio estimado por la Corte Suprema de Chile en varias de sus resoluciones, respecto de ciertas situaciones consideradas como caso fortuito o de fuerza. En una de sus resoluciones se determinó que la estipulación de un plazo de terminación de los contratos de trabajo de los empleados, en virtud del plazo correlativo de revocación dentro de un contrato público, no constituye un elemento imprevisible puesto que al momento de suscribirse tal concesión, tanto los trabajadores como el empleador conocían la existencia de un plazo previamente fijado para su validez. ${ }^{27}$ Con respecto a la misma situación antes descrita, en otro fallo se resolvió que este tipo de eventos, más que fuerza mayor o caso fortuito, constituyen una hipótesis de temporalidad contractual para la terminación de la actividad productiva de una empresa de la cual, tanto trabajadores como empleadores, debían tener conocimiento desde el momento que inició dicha actividad. ${ }^{28}$

Por otra parte, en el caso de la clausura de una empresa en virtud de un acto administrativo emitido por parte de autoridad pública superior, la jurisprudencia chilena determinó que se trata de un evento que puede ser totalmente

25 Juan Luis Castro Jara, "Caso fortuito o fuerza mayor como causal de término de la relación laboral", 15.

26 Coustasse e Iturra, El caso fortuito ante el Derecho Civil, 110.

27 Caso Inostroza c. Inzunza, Rol No. 264-2009, Corte Suprema de Chile , 24 de marzo de 2008, Base Jurisprudencial: www. pjud.cl, también disponible en: http://jurischile.blogspot.com/2008/11/caso-fortuito-y-acto-de-autoridad.html.

28 Caso Mazzo c. Buses Gran Santiago S.A., Causa No. RIT O-2998-2010, Segundo Juzgado del Trabajo de Santiago, Base Jurisprudencial: www.pjud.cl, también en: http://jurischile.blogspot.com/2012/06/indemnización-por-despido.html. 
previsible, puesto que fue el empleador quien puso a su compañía en la situación que provocó la orden de clausura por parte de la autoridad competente. ${ }^{29}$ Lo mismo sucede con la declaración de quiebra de una empresa, que en el ámbito laboral implica esencialmente el cierre del negocio y la consecuente terminación de los contratos de trabajo. En estos casos, la jurisprudencia chilena determinó la inexistencia de configuración de la causal en estudio, ya que el empleador no podía desconocer el estado de sus negocios, lo cual constituye un elemento causal que llevó en definitiva a la declaratoria de quiebra. ${ }^{30}$

Para el caso de un incendio parcial del lugar de trabajo, la jurisprudencia chilena ha descartado que constituya caso fortuito o fuerza mayor para la terminación del contrato individual de trabajo, debido a que solamente provoca una suspensión transitoria y temporal del servicio y, por tanto, el perjuicio económico provocado al empleador no es de tal calidad que le imposibilite de manera permanente proseguir con su actividad habitual. ${ }^{31}$

Para complementar el criterio expuesto, la postura mayoritaria de la doctrina chilena ha enfatizado la importancia de distinguir entre la imposibilidad y la simple dificultad, ya que resulta inconcebible que el empleador sea exonerado de sus obligaciones contractuales porque la continuación de su cumplimiento resulte más difícil u onerosa. La dificultad puede ser vencida mediante el empleo de un mayor esfuerzo, en tanto que la imposibilidad no es superable ni aún con el máximo sacrificio. ${ }^{32}$

En consecuencia, para el ordenamiento jurídico chileno el caso fortuito y la fuerza mayor tienen un régimen de aplicación reservado a la excepcionalidad y no a la generalidad. La integración de las normas fundamentales del Derecho Civil chileno ha sido determinante en materia laboral y sobre todo en la configuración de la causal en estudio. Los elementos de inimputabilidad, imprevisibilidad e irresistibilidad, cuyo desarrollo tuvo mayor relevancia con posterioridad al terremoto de 2010, constituyen su más grande aporte.

29 Caso Herrera c. Sociedad Contractual Minera Tambillos, Causa No. RIT O-253-2009, Juzgado de Letras del Trabajo de La Serena, 27 de noviembre de 2009, Base jurisprudencial: www.pjud.cl, también en: http://jurischile.blogspot. com/2010/09/despido-injustificado-al-aducir-despido.html.

30 Caso Olate c. Empol Chile Say Empol S.A., Rol No. 1270/2006, Corte de Apelaciones de Santiago, 27 de noviembre de 2006, Base jurisprudencial: www.pjud.cl, también en: http://jurischile.blogspot.com/2007/06/despido-injustificado-quienbra-de-la.html

31 Caso Herrera c. Modiglio, Rol No. 4456-2005, Corte de Apelaciones de Santiago, 28 de marzo de 2006, Base jurisprudencial: www.pjud.cl, también en: http://jurischile.blogspot.com/2006/10/incendio-parcial-del-lugar-de-trabajo.html.

32 Coustasse e Iturra, El caso fortuito ante el Derecho Civil, 116. 


\subsection{La causal en estudio en el Derecho español. Paradigma JURídico ANTES Y Después del CoVid-19 ¿Por Qué la SITUACIÓN DE CRISIS ECONÓMICA NO ES CONSIDERADA FUERZA MAYOR EN ESTE SISTEMA?}

Con anterioridad a la pandemia, el literal h) del artículo 49 del Estatuto de los Trabajadores de España, ya establecía el efecto extintivo del contrato de trabajo por fuerza mayor, cuando imposibilite definitivamente la prestación y cumplimiento del mismo siempre que su existencia haya sido debidamente constatada conforme al procedimiento dispuesto desde el numeral $7 \mathrm{de} \mathrm{su}$ artículo $51 .^{33}$

A diferencia del sistema ecuatoriano, el sistema laboral español, prevé un procedimiento en donde intervienen: el empleador, la autoridad laboral competente y el trabajador o trabajadores afectados por dicha causal, a fin de lograr un acuerdo entre las partes. De no existir tal acuerdo, se concederá el derecho a los trabajadores a una indemnización correspondiente a veinte días de salario por cada año de servicio sin que exceda de un máximo de doce mensualidades. ${ }^{34}$

Con ocasión de la pandemia del Covid-19, mediante el Real Decreto-ley 9/2020 35 de 27 de marzo del 2020, en Espańa se adoptaron medidas complementarias al sistema laboral que existía previamente y por lo mismo tendientes a aminorar los efectos derivados de la misma. Dicho instrumento normativo, determinó principalmente, las siguientes medidas emergentes:

[...] 1) la fuerza mayor y las causas económicas, técnicas, organizativas y de producción en las que se amparan los Expedientes de Regulación Temporal de Empleo (ERTE), derivados del Covid-19, no se podrán entender como justificativas de la extinción del contrato de trabajo ni del despido; (...) 2) la suspensión de los contratos temporales, incluidos los formativos, de relevo e interinidad, por las causas derivadas del Covid-19 supondrá la interrupción del cómputo, tanto de la duración de estos contratos, como de los períodos de referencia equivalentes al período suspendido y; (...) 3) todas las solicitudes presentadas por la empresa que contuvieran falsedades o inconsistencias serán sancionadas, así como las conductas tendientes a solicitar medidas, en relación al empleo que no resultaren necesarias o no tuvieran conexión suficiente con la causa que las origina y que den lugar a la generación o percepción de prestaciones indebidas. ${ }^{36}$

33 Artículos 49 y 51, Ley Estatuto de los Trabajadores de Espańa, Boletín Oficial del Estado Número 225 de 23 de octubre de 2015, reformado por última vez 27 de mayo de 2020, https://www.boe.es/eli/es/rdlg/2015/10/23/2/con .

34 Guillermo Cabanellas de las Cuevas, Tratado de Derecho Laboral. Derecho Individual del Trabajo. Contrato de Trabajo (Buenos Aires: Editorial Heliasta,1988), 47.

35 Real Decreto-ley 9/2020, Boletín Oficial del Estado, Núm. 86, Sección I, Pág. 27548: https://www.boe.es/boe/ dias/2020/03/28/pdfs/BOE-A-2020-4152.pdf.

36 Rosa Zarza, "La fuerza mayor y las causas de suspensión de contrato derivadas del Covid-19 no se podrán entender como justificativas de despido." GARRIGUES, (marzo 2020). https://www.garrigues.com/es_ES/noticia/la-fuerza-mayor-y-lascausas-de-suspension-de-contrato-derivadas-del-covid-19-no-se-podran. 
Las medidas emergentes incluidas en este instrumento coinciden con el sistema ecuatoriano al establecer sanciones a la invocación injustificada de esta causal y determinar un efecto suspensivo del contrato de trabajo. España descarta la procedencia de la causal en situaciones de crisis económica. Asimismo, determina la existencia de un procedimiento reglado y esencialmente contradictorio entre las partes. En cambio, en Ecuador basta con el registro de los fundamentos de la causal en estudio y su posterior notificación al trabajador, para dar por terminado el contrato individual de trabajo. De igual manera, dado que varios empleadores en el Ecuador han optado por la invocación de esta causal por situaciones de crisis económica, si en dicho país tuviéramos que aplicar lo dispuesto por el Real Decreto-ley español, podría decirse que la gran mayoría de estas invocaciones resultarían automáticamente injustificadas, desencadenando en consecuencia los efectos del despido intempestivo y su indemnización correspondiente. Sin perjuicio de que en el Ecuador no exista una disposición como la que se encuentra en el Real Decreto-ley español, vale decir que, no solo la crisis económica sino todos los fundamentos que podría tener la causal en estudio, deberían ser discutidos ante la autoridad administrativa competente, previo a declararse la configuración de dicha causal. Sin embargo, esto se vuelve imposible al no existir un procedimiento reglado para este tema, reservando su reclamo únicamente en la vía judicial respectiva.

\subsection{LA CAUSAL DE FUERZA MAYOR O CASO FORTUITO EN EL DERECHO LABORAL MEXICANO. REQUISITOS PARA SU PROCEDENCIA. ¿UNA GUÍA DE PROCEDIMIENTO Y SUSTANCIACIÓN IGNORADA?}

El artículo 434 de la Ley Federal del Trabajo de México ${ }^{37}$, determina al caso fortuito y a la fuerza mayor, como causales de terminación de las relaciones laborales, cuando aquellos no sean imputables al empleador o a su incapacidad física o mental -o incluso a su muerte-, que produzca además, como una consecuencia necesaria, inmediata y directa; la terminación de los contratos de trabajo.

De conformidad con lo establecido en el artículo $435^{38}$ del cuerpo legal antes mencionado, la invocación de la causal en estudio para la terminación de los contratos de trabajo exige la evaluación y posterior aprobación por parte de la Junta de Conciliación y Arbitraje, como autoridad competente, a través de un procedimiento reglado. Si esta causal ha sido invocada justificadamente, se concede a los trabajadores una indemnización de 3 meses de salario más

\footnotetext{
37 Artículo 434, Ley Federal del Trabajo de México, Diario Oficial de la Federación de 1 de abril de 1970, reformado por última vez Diario Oficial de la Federación de 2 de julio de 2019: http://www.diputados.gob.mx/LeyesBiblio/ pdf/125_020719.pdf.

38 Artículo 435, Ley Federal del Trabajo de México, 1970.
} 
una prima de antigüedad equivalente a doce días de salario por cada año de servicio. ${ }^{39}$ Lo antes descrito, al igual que en España, implica la existencia de un régimen indemnizatorio compensatorio en favor de los trabajadores, todo lo cual resulta de la existencia correlativa de un procedimiento reglado y de la determinación de una autoridad sustanciadora para tal efecto. En Ecuador, ninguno de estos supuestos podría cumplirse, pues no se contempla procedimiento alguno, ni mucho menos se ha designado a una autoridad competente. Dejar a salvo la acción pertinente, únicamente en vía judicial, representaría para el Ecuador un problema jurídico respecto al cumplimiento de, entre otros, el principio de economía procesal y garantía constitucional de los derechos.

Conforme a lo dispuesto por los artículos $897^{40}$ y siguientes de la Ley Federal de Trabajo en México, el procedimiento de sustanciación de la causal en estudio se inicia con la presentación de una demanda por parte del empleador que invoca dicha causal. Posteriormente, tendrá lugar la contestación a dicha demanda por parte del trabajador o los trabajadores afectados por la invocación de esta, en los términos y plazos determinados para tal efecto. Así, cada parte tendrá derecho a una réplica y contrarréplica de forma escrita. A continuación, se llevará a cabo la audiencia de juicio para la práctica y producción de las pruebas. Y, finalmente, se anunciará oralmente la resolución, y será notificada por escrito en el término legal establecido. Contra esta resolución no cabrá recurso alguno en sede administrativa, dejándose a salvo solo la acción judicial pertinente.

Evidentemente, a partir de lo analizado en el sistema mexicano, se podrá encontrar la relevancia jurídica que implica incorporar un procedimiento especial para la sustanciación de la causal en estudio, pues precisamente al ser los derechos de los trabajadores una garantía por antonomasia constitucional, se requiere una diferenciación en el tratamiento procedimental de la misma, cuestión a la cual el Ecuador ha hecho caso omiso.

\subsection{LA RELEVANCIA DE LA TEMPORALIDAD DE LOS EFECTOS DE LA CAUSAl EN El DERECHO SALVADOREÑo ¿UNA DUALIDAD CIRCUNSTANCIAL PARA SU APLICACIÓN?}

De conformidad con el numeral 6 del artículo $48^{41}$ del CT de El Salvador, la fuerza mayor o caso fortuito constituyen una causal de terminación o conclu-

39 Cabanellas, Tratado de Derecho Laboral, 48.

40 Artículo 897, Ley Federal del Trabajo de México, 1970.

41 Artículo 48 numeral 6, Código de Trabajo de la República de El Salvador, Diario Oficial No. 142, Tomo 236 de 31 de julio de 1972, reformado por última vez Decreto Legislativo D.L No. 611, de 16 de febrero de 2005, publicada en el Diario Oficial D.O No. 55, Tomo 366 de 18 de marzo del 2005: https:/www.ilo.org/dyn/travail/docs/1742/Cod_Trab_ElSalv\%5B1\%5D.pdf. 
sión del contrato de trabajo sin acarrear ni generar responsabilidad para las partes contratantes, siempre y cuando sus consecuencias no sean imputables al empleador y siempre que produzcan necesariamente la terminación de todo o parte del negocio. Sin embargo, antes de que se configure lo anterior, los artículos 33, 34 y $36^{42}$ del mencionado cuerpo legal, establecen dos situaciones que pueden surgir con la ocurrencia de un evento que se repute como caso fortuito o de fuerza mayor en función de una valoración de temporalidad respecto de las consecuencias que produzca. La primera situación tiene lugar cuando la causal en estudio produce un efecto suspensivo ya que el hecho ha provocado que el trabajo deje de prestarse en un plazo que no exceda de tres días. La segunda situación tiene lugar cuando la causal en estudio produce, en cambio, consecuencias en la modalidad del contrato generando así la reducción emergente de la jornada laboral ordinaria de trabajo.

Para ambas situaciones, el análisis de imputabilidad del empleador es preponderante, pues en caso de verificarse que el empleador es imputable de las consecuencias ocasionadas, éste tiene la obligación de pagar a sus trabajadores afectados un valor adicional equivalente al que dejaren de devengar con ocasión de la reducción de la jornada laboral adicional a su salario regular. Por el contrario, si las consecuencias del caso fortuito o fuerza mayor no son imputables al empleador, éste deberá pagar a los trabajadores solo el cincuenta por ciento del valor que dejaren de devengar, además del salario por el tiempo trabajado. En virtud de estas dos situaciones dependientes del efecto de temporalidad, puede verificarse que cuando se trata de efectos totalmente extintivos del contrato de trabajo, la aplicación de la causal en estudio se reserva solo para eventos que acarreen consecuencias permanentes. De manera que los contratos de trabajo son terminados o concluidos por excepcionalidad y no desde la generalidad de la aplicación de la causal mencionada.

$\mathrm{Al}$ respecto, Cabanellas considera necesario recurrir a la prueba de los efectos de la fuerza mayor o el caso fortuito sobre el negocio, que, si bien no debe producir una imposibilidad absoluta como los sistemas previamente estudiados, sí debe guardar una relación objetiva y causal entre el hecho pretendido como caso fortuito o de fuerza mayor, y su repercusión con respecto a la terminación total o parcial del negocio. ${ }^{43}$ Por lo tanto, es evidente que la configuración de esta causal necesita de varias instancias de evaluación, tanto de autoridades administrativas como judiciales, sobre la base de todos los elementos que han sido recogidos de las legislaciones analizadas. Resulta llamativo que el sistema ecuatoriano haya optado por el régimen de aplicación general de la causal en estudio, dejando al arbitrio del empleador optar por la terminación definitiva del contrato o, en su defecto, por la suspensión o reducción de la jornada

42 Artículos 33, 34 y 36, Código de Trabajo de la República de El Salvador, 1972.

43 Cabanellas, Tratado de Derecho Laboral, 46. 
laboral, sin mayor consideración proactiva de sus elementos configurativos. Hasta el momento, todos los sistemas jurídicos en materia laboral han coincidido en la determinación de la imputabilidad del empleador en el hecho que se aduce como fortuito o de fuerza mayor, para lo cual existe un procedimiento especial reglado, una autoridad competente sustanciadora y un régimen indemnizatorio dependiente de la procedencia de la causal. Sin embargo, todos estos elementos no han sido considerados por la legislación ecuatoriana, a pesar de serle esencialmente inherentes.

\subsection{El REQUisito de EVALUACIÓN DE La CONDUCTa Y VOLUNTAD DEL EMPLEADOR PARA LA CONFIGURACIÓN DE LA CAUSAL EN EL DERECHO BRASILEÑO. EL RÉGIMEN DE VALORACIÓN DEL IMPACTO DEL HECHO EXTERNO Y RÉGIMEN INDEMNIZATORIO ESCALONADO.}

La Consolidación de las Leyes de Trabajo (CLT) de Brasil, establece en su artículo $501^{44}$ que se entenderá como fuerza mayor todo acontecimiento inevitable en relación con la voluntad del empleador. En otras palabras, para la realización de este acontecimiento inevitable se requiere que el empleador no haya concurrido de forma directa ni indirecta. Así, el numeral 1 del referido artículo, dispone que en caso de existir, configurarse o demostrarse el elemento negligencia o imprevisión por parte del empleador, se anula completamente el caso fortuito o la fuerza mayor. Por lo mismo, toda terminación de la relación laboral por esta causal, se convertirá automáticamente en un despido intempestivo. El numeral 2 del mismo artículo determina que cuando la ocurrencia de la fuerza mayor no produzca una afectación sustancial, ni tampoco sea susceptible de producir una afectación de forma probable con respecto a la situación económica y financiera de una empresa, el régimen de terminación del contrato de trabajo en virtud de la causal en estudio, tampoco tiene cabida alguna.

Al igual que lo referido en los sistemas español, salvadoreño y mexicano, las leyes de trabajo de Brasil prevén también un sistema indemnizatorio escalonado cuando se procede con la terminación del contrato de trabajo por fuerza mayor. Por ejemplo, el artículo $502^{45}$ del cuerpo normativo laboral brasileño establece que en caso de fuerza mayor que produzca la extinción de la empresa o de uno de sus establecimientos en donde laboran los trabajadores, se les garantizará una compensación correspondiente al pago de todos los valores proporcionalmente devengados, así como la mitad del valor indemnizatorio que les correspondería por despido intempestivo.

44 Artículo 501, Consolidación de las Leyes de Trabajo de Brasil, Diario Oficial de 14 de julio de 2017, Senado Fed. Brasileño: https://www2.senado.leg.br/bdsf/bitstream/handle/id/535468/clt_e_normas_correlatas_1ed.pdf.

45 Artículo 502, Consolidación de las Leyes de Trabajo de Brasil, 2017. 
En este aspecto, el sistema brasileño trata una situación de extinción de una empresa, que no es lo mismo que la situación de imposibilidad o cese definitivo de la actividad productiva de la que trata el sistema ecuatoriano. Por otro lado, es destacable que en Brasil se refiera también a la extinción de uno de los establecimientos, cuando se trata de empresas que han alcanzado mayor tamaño económico, que al parecer implica una situación más coherente para la demostración y prueba del hecho, a diferencia de la complejidad procesal que podría representar demostrar una situación de imposibilidad para los empleadores dentro de un potencial proceso judicial.

En contraste con lo anterior, el artículo 503 del código laboral brasileño ${ }^{46}$, contempla una alternativa por el avenimiento de un evento que configure esta causal, diferente a la exclusividad de la terminación. Así, se determina también la reducción de los salarios generales de los empleados de una empresa, de conformidad a un cálculo proporcional al salario de cada persona sin que dicha reducción exceda el 25\%. El límite para esta reducción es la intangibilidad e inmutabilidad del salario mínimo establecido, existiendo la obligación de la restauración al estado anterior de los sueldos y salarios, una vez que los efectos de la fuerza mayor hayan cesado, manteniendo así un régimen mayormente verificable de sostenibilidad del trabajo ante este tipo de eventos.

Finalmente, de conformidad al artículo 504 de las Leyes de Trabajo de Brasil ${ }^{47}$, en caso de que la invocación de esta causal por parte del empleador sea falsa, la reintegración de los empleados será inmediata y su remuneración complementaria a la compensación percibida queda garantizada y operará de manera obligatoria, así como también el pago de haberes atrasados o en mora del empleador.

Es importante resaltar que el sistema brasileño -al igual que el sistema español- prevé un efecto extintivo del contrato de trabajo cuando la causal en estudio es verificada eficazmente. De igual forma es menester señalar que este sistema comparte similitud con las indemnizaciones escalonadas que corresponden a los trabajadores en los sistemas mexicano y salvadoreño, indistintamente de la temporalidad del hecho. Asimismo, el sistema brasileńo resalta también la importancia de la determinación del elemento imputabilidad del empleador y, al igual que el Ecuador, también establece, por un lado, una sanción por haberse recurrido de forma fraudulenta a la aplicación de la causal en estudio, y por otro, un efecto reductivo de la jornada, únicamente diferente en el porcentaje límite de reducción contemplado.

46 Artículo 503, Consolidación de las Leyes de Trabajo de Brasil, 2017.

47 Artículo 504, Consolidación de las Leyes de Trabajo de Brasil, 2017. 
El análisis de los efectos materiales y temporales que puede ocasionar un evento atribuible a la fuerza mayor o al caso fortuito es de esencial relevancia, pues demuestra que la invocación de la causal en estudio sigue un régimen de aplicación excepcional y no general, para lo cual se prevé un régimen de aplicación especial para cada caso, dejando nuevamente a la terminación del contrato de trabajo como una medida de ultima ratio. Esta especificidad en la determinación de una evaluación previa en función de la temporalidad y materialidad de los efectos de la pandemia, es un elemento claramente ausente en el sistema ecuatoriano, que incluso limita a los trabajadores afectados por esta causal, exclusivamente a la tutela y reconocimiento de sus derechos en una sentencia judicial, dependiente de los tiempos que esto acarree.

\subsection{EFECTOS DE LA FUERZA MAYOR O EL CASO FORTUITO EN EL CONTRATO DE TRABAJO EN LA LEGISLACIÓN ARGENTINA. Procedimiento para su configuración. Desarrollo JURISPRUDENCIAL Y DOCTRINARIO DE LOS CASOS EJEMPLIFICATIVOS DE ESTOS EVENTOS. ¿LA CRISIS ECONÓMICA NUEVAMENTE DESCARTADA COMO FUERZA MAYOR O CASO FORTUITO?}

$\mathrm{Al}$ igual que en los sistemas salvadoreño y brasileño, la causal en estudio dentro del sistema laboral argentino determina dos momentos en función de un análisis de temporalidad. Así, puede distinguirse en primer lugar una implicación previa con efecto suspensivo y, por otro lado, una consecuencia posterior, con efecto extintivo del contrato de trabajo. Con respecto al primer caso, el artículo 221 de la Ley de Contrato de Trabajo de Argentina, prevé que las suspensiones por fuerza mayor debidamente comprobadas podrán extenderse hasta un plazo máximo de setenta y cinco días en el término de un año, contado desde la primera suspensión, indistintamente de cuál sea el motivo de esta, aplicando criterios de antigüedad para su dosificación salarial. ${ }^{48}$ En relación al efecto extintivo, el artículo 247 de la Ley de Contrato de Trabajo argentina, establece una dualidad idéntica tanto para el caso en que el despido fuese dispuesto por causa de fuerza mayor, como si es ocasionado por disminución de trabajo, siempre que ambas situaciones no sean imputables al empleador. Verificado este escenario, el trabajador tendrá derecho a recibir una indemnización equivalente a la mitad del monto que le correspondería por un despido injustificado o intempestivo. ${ }^{49}$

48 Artículo 221, Ley de Contrato de Trabajo de Argentina, Boletín Oficial de la República Argentina de 5 de diciembre de 2013, Aprobada mediante Ley No. 20.744, ordenado por Decreto No. 390/1976 de 13 de mayo de 1976, http://servicios. infoleg.gob.ar/infolegInternet/anexos/25000-29999/25552/texact.htm.

49 Artículo 247, Ley de Contrato de Trabajo de Argentina, 2013. 
Para completar estas dos modalidades, el artículo $231^{50}$ del mismo cuerpo legal prevé la obligación del preaviso que debe dar una parte a la otra respecto de su voluntad de disolver el contrato de trabajo en virtud de la causal en estudio, preaviso sin el que cualquier decisión tendiente a este efecto no tiene validez alguna y en virtud de la cual se establece un régimen indemnizatorio mayor, determinado en función escalonada por antigüedad.

En el derecho laboral argentino, el preaviso por parte del empleador es obligatorio para proceder a la extinción del contrato de trabajo, con un término de 15 días de anticipación, para el caso en que el trabajador se encontrare en período de prueba. En un término de 1 mes cuando el trabajador tuviese una antigüedad en el empleo que no exceda de 5 años. Y finalmente, un término de 2 meses para el caso en que el período de estabilidad del trabajador fuere superior a los 5 ańos. ${ }^{51}$ Este sistema está previsto en Argentina con el único objetivo de que el trabajador disponga de un tiempo prudencial para conocer los fundamentos de la invocación de esta causal y preparar su defensa y pruebas de descargo. Así como ocurre en España y México, en Argentina el conocimiento y competencia de dicho procedimiento está a cargo de una autoridad pública, el Ministerio de Trabajo de la Nación, dejando a salvo posteriormente las acciones judiciales que tuvieren lugar.

En este punto, puede encontrarse una vaga similitud con lo establecido por el Ministerio de Trabajo ecuatoriano, respecto al requisito de registro de los fundamentos de la causal en estudio, para proceder a dar por terminado el contrato de trabajo por parte del empleador, y posteriormente notificarlo a su trabajador. Sin embargo, a diferencia del preaviso argentino, en el Ecuador no se ha establecido un tiempo prudencial para que el trabajador afectado prepare una defensa ante la invocación de la causal en estudio, precisamente por no existir un procedimiento reglado para tal efecto. En lo único que coincide el sistema ecuatoriano con el argentino, es en haber dejado a salvo las acciones judiciales pertinentes.

La jurisprudencia argentina, destaca nuevamente el análisis de la imputabilidad del empleador en la invocación de la causal en estudio, pero con algunos matices diferentes. En su esencia, puede darse la situación de que no exista materialmente un acto por parte del empleador que conduzca inmediatamente a la configuración del hecho que impide continuar con la relación de trabajo, sino que el empleador, por una administración deficiente, haya colocado a su empresa en una situación en la que resulta imposible continuar con sus actividades. Mientras ciertos fallos tienden a enfocar su atención a efectos de

50 Artículo 231, Ley de Contrato de Trabajo de Argentina, 2013.

51 Artículo 231, Ley de Contrato de Trabajo de Argentina, 2013. 
determinar si existe fuerza mayor o caso fortuito no imputable al empleador en la intención y efectos deseados por éste, ${ }^{52}$ otros fallos analizan el curso de las actividades del empleador, que conduce a la situación de fuerza mayor o caso fortuito, no requiriendo para que éste sea imputable de la existencia de un acto concreto e intencionado de su parte que le dé origen, siendo suficiente su imprudencia o negligencia. ${ }^{53}$

Cabanellas considera correcto el criterio expuesto por la segunda postura jurisprudencial, pues podría decirse que la conducta del empleador difícilmente conduce a situarse en una posición de imposibilidad de continuar la relación laboral, o que surja de un único acto preciso y evidentemente dirigido a configurar tal situación. Este autor considera que la causal en estudio rara vez constituye un impedimento absoluto, sino que más bien, tiende a crear un incremento súbito en la onerosidad de la relación laboral..$^{54}$

En adición a esta postura doctrinaria, la jurisprudencia argentina también ha desarrollado la procedencia de dicha causal, respecto a los presupuestos fácticos determinados para ciertos casos que las legislaciones consideran como ejemplos de este tipo de situaciones. Así, en el caso de una orden de autoridad, o de actos derivados de la actividad pública o incluso en el mismo ejercicio de soberanía por parte de una institución del Estado en sentido laxo que produzca el cese de actividades de una empresa o un empleador, podría configurarse eficazmente la causal en estudio, por ser independiente de la voluntad de las partes. ${ }^{55}$ En cambio, otros fallos han determinado que la expropiación por utilidad pública no constituye caso fortuito o fuerza mayor que libere al expropiado del pago de indemnizaciones a sus dependientes, pues está justificado por tratarse de un procedimiento amparado por la Constitución y la ley especial de la materia; por tanto, encuentra su legitimidad en el principio social de utilidad pública y el principio de competencia que rige la administración pública. ${ }^{56}$ En ese sentido, en Argentina se ha resuelto también que si el Estado adquiere un establecimiento industrial, cambia completamente el régimen jurídico de los empleados, pues pasan a ser públicos, y, por ello, opera

52 Caso Demarchi Edgardo Hernán y Otros c. Muscio Enrique José, s/ Despido, Cámara Nacional de Apelaciones del Trabajo, Capital Federal, Ciudad Autónoma de Buenos Aires, Sala VI, 27 de julio de 1979, pág.1168, http://www.saij.gob. ar/camara-nacional-apelaciones-trabajo-nacional-ciudad-autonoma-buenos-aires-demarchi-edgardo-hernan-otros-muscio-enrique-jose-despido-fa79041568-1979-07-27/123456789-865-1409-7ots-eupmocsollaf?.

53 Caso Córdoba Jorge Enrique y Otro c. Atlanta SAIC, Cámara Nacional de Apelaciones del Trabajo. Capital Federal Ciudad Autónoma de Buenos Aires, Sala VII, 13 de mayo de 1982, pág.1228,

http://www.saij.gob.ar/despido-falta-disminucion-trabajo-personal-contratado-sue0000730/123456789-0abc-defg0370 -000esoiramus? \&o=106\&f=Total\%7CFecha/1982/05\%7CEstado\%20de\%20Vigencia\%5B5\%2C1\%5D\%7CTema $\%$ 5B5\%2C1\%5D\%7COrganismo\%5B5\%2C1\%5D\%7CAutor\%5B5\%2C1\%5D\%7CJurisdicci\%F3n/Nacional\%7CTribunal\%5B5\%2C1\%5D\%7CPublicaci\%F3n\%5B5\%2C1\%5D\%7CColecci\%F3n\%20tem\%E1 tica\%5B5\%2C1\%5D\%7CTipo\%20de\%20Documento/Jurisprudencia\&t=146\#.

54 Cabanellas, Tratado de Derecho Laboral, 50.

55 Ibid., 50-54.

56 Ibid., 50-54. 
la disolución del contrato primitivo por voluntad de las partes y únicamente se debe proceder con el pago de las indemnizaciones correspondientes a esta disolución. ${ }^{57}$

Para el caso del incendio, de acuerdo con esta jurisprudencia, no todos ellos constituyen un evento de caso fortuito o de fuerza mayor, ya que esencialmente este evento puede ser evitado; y aún así fuere puramente accidental, resulta perfectamente previsible como riesgo propio del negocio y que además es económicamente solucionable en virtud del seguro que se debería contratar para precaver estos efectos. ${ }^{58}$

Con respecto a la crisis económica, la jurisprudencia argentina sostiene que aquella no constituye caso fortuito o fuerza mayor en su esencia, sino que podría configurar un elemento que incida a posteriori sobre la estructura de una empresa, produciendo en consecuencia tal fuerza mayor o caso fortuito. Por lo que nuevamente el examen de la negligencia previa del empleador por haber conducido a la empresa a dicha crisis se vuelve fundamental. ${ }^{59}$

Para la jurisprudencia argentina, tampoco existe caso fortuito o fuerza mayor cuando la empresa experimenta pérdidas pero mantiene su ritmo productivo, ni cuando cierra un establecimiento o sucursal pero mantiene en funcionamiento a los restantes; tampoco cuando sufre una caída de la demanda productiva, mientras el resto de las empresas de la competencia están en expansión; ni mucho menos cuando la empresa ha omitido las precauciones necesarias para hacer frente a las modificaciones técnicas indispensables o desplazamientos previsibles de la demanda. ${ }^{60}$

En función de lo referido hasta el momento, existen tres elementos en los cuales el Ecuador coincide con las legislaciones revisadas: primero la situación de imposibilidad absoluta o cese definitivo de la actividad productiva del empleador; segundo, un coeficiente aumentado de indemnización por invocación injustificada de la misma; y finalmente, el hecho de dejar a salvo la acción judicial que tuviere lugar. Sin embargo, el Ecuador no ha precisado un procedimiento especial y reglado para la sustanciación de la causal en estudio, tampoco ha determinado una autoridad con la competencia correspondiente, peor aún un régimen de aplicación excepcional que podría complementarse con una determinación específica respecto de las situaciones o eventos, en los cuales dicha causal hubiese sido procedente, o al menos en su defecto, establecer que la crisis económica de la parte empleadora no signifique un presupuesto para su configuración, criterio compartido por las legislaciones previamente descritas. 


\section{LA TEORÍA DE LA RESPONSABILIDAD CIVIL SUBJETIVA Y OBJETIVA PARA LA CONFIGURACIÓN DE LA CAUSAL EN ESTUDIO. ¿ES NECESARIO INCLUIR EL ELEMENTO IMPUTABILIDAD DEL EMPLEADOR EN EL SISTEMA LABORAL ECUATORIANO?}

Conforme al análisis comparativo realizado, la configuración eficaz de la causal en estudio debe producir una situación externa imprevisible, o que, siendo prevista, no haya sido posible evitar; así como la imposibilidad de continuar la relación laboral o el cumplimiento de sus obligaciones, sin que medie negligencia por parte del empleador. Es evidente entonces, que esta unión conceptual resultará esencial para la determinación de la fuerza mayor o el caso fortuito, pues una efectiva demostración de la configuración de esta causal llevará a la autoridad competente al convencimiento de todos los esfuerzos utilizados por el empleador para evitar las consecuencias de un hecho que se aduce imprevisible; de otra forma, este elemento no estará completo ni logrará dicho objetivo. ${ }^{61}$

Por lo tanto, en la esfera jurídica laboral, las diversas legislaciones analizadas coinciden en que el caso fortuito o fuerza mayor no deben haber tenido origen en la conducta del empleador. En otras palabras, no puede éste, mediante sus actos, poner a su empresa en una posición tal que impida continuar la relación laboral, para luego oponer ese impedimento a los reclamos del trabajador. Según la doctrina, si ex ante el empleador ha conducido su empresa con desatino financiero o irregularidades en su negocio, para alegar ex post esta causal, la causal en estudio carece de toda configuración. Lo cual, a manera de ejemplo, se precisa en dos situaciones: cuando el empleador sufriese la clausura de su establecimiento como consecuencia del incumplimiento de normas de orden público, o en el caso en que sea desalojado del local donde desarrolla sus actividades por no obtener la renovación de su licencia. ${ }^{62}$

En consecuencia, con base en la doctrina chilena, podría integrarse fácilmente la teoría de la responsabilidad civil subjetiva a la causal en estudio, pues dicha doctrina concibe al caso fortuito y a la fuerza mayor en un sentido estrictamente subjetivo, esto es, como negación o inexistencia de culpa por parte del agente que los invoca, produciendo la exoneración de responsabilidad como consecuencia de la extinción o terminación de un contrato por imposibilidad de su cumplimiento. ${ }^{63}$

61 Ibid., 50-54

62 Juan Carlos Fernández, Madrid: La imputabilidad de la causa en los despidos por cierre de negocio. Legislación del Trabajo, Tomo XVIII, 860. Ver: Guillermo Cabanellas, Tratado de Derecho Laboral. Derecho Individual del Trabajo. Contrato de Trabajo. Volumen III, Tomo II, Tercera Edición (Buenos Aires: Editorial Heliasta, 1988), 49.

63 Juan Luis Castro Jara, "Caso fortuito o fuerza mayor", 21. 
Integrando la doctrina antes mencionada en materia laboral, la ausencia de dolo o culpa del empleador en la imposibilidad de cumplir el contrato, sería suficiente para configurar la causal en estudio. Análisis que deberá realizarse sobre el deber de ocupación efectiva y adecuada, que emana del carácter personal del contrato de trabajo, en virtud del cual el empleador debe cumplir ciertas obligaciones dispuestas en la ley para proteger a su trabajador. ${ }^{64}$ En virtud de este deber, el empleador se encuentra obligado a otorgar el puesto de trabajo y es precisamente ésta la obligación que se hace imposible de cumplir como consecuencia de la causal en estudio. De este modo, siendo el empleador el deudor de la obligación de dar el trabajo convenido a su trabajador, esta causal no tendría diferencia alguna con el régimen de exención de responsabilidad establecida por el Derecho Civil, debiendo el empleador responder hasta de la culpa leve en el cumplimiento de sus obligaciones contractuales. ${ }^{65}$

Por este motivo, en atención a la jurisprudencia chilena en materia laboral, es fundamental un juicio de reproche sobre la evaluación de la negligencia del empleador, respecto del hecho que se reputa como fortuito o de fuerza mayor, al momento de determinar la configuración de la causal en estudio. ${ }^{66}$ Podría decirse entonces que el hecho es inimputable cuando es imprevisible o imposible de resistir. De lo contrario, mal podría decirse que el suceso es totalmente ajeno a la conducta negligente del empleador, siendo esencial que estos elementos resulten de la comparación que se haga respecto de los distintos grados de diligencia que este debió haber empleado frente al acontecimiento.

Por lo mismo, la debida diligencia del empleador, como presupuesto fundamental de la configuración de su inimputabilidad, debe estar integrada por el conjunto de precauciones racionales que toman los hombres prudentes en su conducta, adicional a la previsión y el cuidado necesarios para que el hecho externo -imprevisible e irresistible- no llegue a producir consecuencias dañosas. ${ }^{67}$ Lo anterior justifica que las consecuencias de determinado incumplimiento, así como sus causas eximentes, se conciban relativas a la existencia o ausencia de un criterio de imputación de dicho incumplimiento sobre el empleador, es decir, su culpa o negligencia, pues aquellas se presumen de hecho en el incumplimiento de un contrato y las consecuencias de este se consideran sanciones impuestas al empleador que ha incurrido en una conducta antijurídica. ${ }^{68}$

En definitiva, integrar la teoría de la responsabilidad civil subjetiva en la esfera jurídica laboral para la configuración de la causal en estudio, implica demos-

64 William Thayer Arteaga y Patricio Novoa Fuenzalida, Manual de Derecho Individual de Trabajo, (Santiago de Chile: Editorial Jurídica de Chile, 1998), 550.

65 Castro Jara, "Caso fortuito o fuerza mayor", 21

66 Ibid., 22.

67 Victoria Rodríguez, El caso fortuito ante la jurisprudencia chilena (Santiago: Editorial Universitaria, 1964), 14

68 Fernando Fueyo Laneri, Cumplimiento e Incumplimiento de las obligaciones (Santiago: Editorial Jurídica de Chile, 2004), 256. 
trar la ausencia de culpa o negligencia por parte del empleador. Esto conlleva a realizar un juicio de reproche sobre su actuar en una línea de trazabilidad delimitada por el antes, durante e incluso después -dependiendo del casorespecto del evento que se presume como caso fortuito o fuerza mayor.

Ahora bien, frente a esta visión clásica integrada desde el Derecho Civil a la causal en estudio en materia laboral, nuevas corrientes han determinado algunos planteamientos que sostienen la necesidad de objetivar la noción de caso fortuito o fuerza mayor, desvinculándolos de su noción subjetiva de culpa o negligencia exclusivamente, lo cual se manifiesta fundamentalmente en la verificación de la exterioridad del hecho. ${ }^{69}$

Según la doctrina, lo anterior implica la posibilidad de reformular la concepción del elemento imputabilidad a través de un nuevo enfoque, permitiendo así una cierta objetivación del concepto de caso fortuito o fuerza mayor, demostrando que dicho concepto, si bien está estrechamente vinculado con el deber de diligencia, no sería simplemente la negación o ausencia de culpa, su único parámetro de análisis. ${ }^{70}$ En tal virtud, el análisis de la exterioridad del hecho consistiría en la ausencia del vínculo causal entre la conducta del empleador y el hecho que ocasione el incumplimiento contractual. Así, la prueba de la causal en estudio debería dirigirse a demostrar la diligencia y cuidado del empleador en el cumplimiento de sus obligaciones sobre un contexto circunstancial, que lo desvincule de la eventual causalidad. Vivanco considera que la incorporación de las teorías de responsabilidad civil objetiva y subjetiva en materia laboral, representarían un paliativo a este paradigma, desde que el empleador es quien deberá, para exonerarse de la obligación de indemnizar, rendir prueba conducente para acreditar que actuó con la debida diligencia y cuidado en el cumplimiento de sus obligaciones, por cuanto es éste quien ha invocado la causal en estudio. ${ }^{71}$

Podría decirse entonces que todo lo que ha sido expuesto en esta sección, guarda estrecha relación con lo establecido en las legislaciones comparadas. En el ámbito subjetivo de la norma, se ha determinado como requisito fundamental la ausencia de culpa o negligencia por parte del empleador en la invocación de la causal en estudio privándole, de este modo, beneficiarse de su propio actuar deficiente que afecta a sus trabajadores. Asimismo, todo lo analizado en las legislaciones comparadas, guarda estrecha relación con la teoría de la exterioridad del hecho, toda vez que, si es el empleador quien invoca la causal en estudio, es sobre este en quien recae la carga probatoria de la misma y de sus elementos configurativos, y no en el trabajador. Así, el juicio de reproche del empleador en el manejo de su empresa o, en general, respecto de sus obli-

69 María Graciela Brantt Zumarán, El caso fortuito y su incidencia en el derecho de la responsabilidad civil contractual: concepto y función del caso fortuito en el código civil chileno (Santiago: Editorial Abeledo Perrot Legal Publishing, 2010), 22.

70 Ibid., 54.

71 Manuel Vivanco Cisternas, El despido laboral (Santiago: Editorial Jurídica de Chile, 1994), 29. 
gaciones en la relación laboral, puedan desvincularlo del nexo causal que lo ataría a determinado hecho que se pretenda como fortuito o de fuerza mayor.

Por otro lado, en el ámbito objetivo de la norma, es decir el procedimiento por el cual sus disposiciones adquieren aplicabilidad jurídica, resultará fundamental realizar el análisis de la imputabilidad del empleador desde la teoría de la responsabilidad civil subjetiva, es decir su ausencia de culpa, así como desde la teoría de la responsabilidad civil objetiva, en función del cumplimiento de sus obligaciones como empleador frente a la exterioridad del hecho, dentro del nexo causal antes referido.

En consecuencia, la necesidad de integrar estas dos teorías de la responsabilidad civil, en la esfera jurídica laboral ecuatoriana, a pesar de no haberse contemplado un procedimiento de impugnación -al menos en sede administrativa- constituye un parámetro sobre el cual se deben establecer los lineamientos o estrategias de defensa para cada parte dentro del proceso judicial que tuviere lugar. Asimismo, a pesar de que el desarrollo jurídico de la causal en estudio siga siendo incompleto en el Ecuador, la integración de ambas teorías de la responsabilidad civil para este caso en particular en materia laboral, constituye el cumplimiento del deber fundamental de interpretación e integración encomendado por el maestro Kelsen a los profesionales del Derecho.

\section{Conclusiones}

El desarrollo jurídico de la causal en estudio en el Ecuador ha sido escaso, incluso antes de la pandemia del Covid-19. La LOAH no ha solucionado de forma suficiente la aplicación efectiva de dicha causal, por limitar su aplicación a un único parámetro para su procedencia, omitiendo así una serie de elementos que deberían también serle inherentes. Lo anterior demuestra una calidad legislativa que se encuentra fuera de un contexto sistemático que permita una mejor funcionalidad, procedencia y aplicación de esta causal que, a pesar de los esfuerzos realizados, sigue siendo insuficiente.

Es necesario que el sistema ecuatoriano incorpore a su ordenamiento un procedimiento especial y reglado para la sustanciación y resolución, al menos en sede administrativa, de la causal en estudio. Dicho procedimiento debe garantizar la igualdad de condiciones, el respeto al debido proceso y ser esencialmente contradictorio, tal como se ha visto en las legislaciones analizadas, y no solamente cumplir con dejar a salvo las acciones judiciales que tuvieren lugar.

Asimismo, es necesario que se incorpore la especificidad en la determinación de la temporalidad, producto del impacto de la causal en estudio. Es ineficaz para el Ecuador prever una aplicabilidad generalizada, y se debería optar por 
mecanismos tendientes a una procedencia excepcional que cumpla efectivamente el ideal detrás de la LOAH.

Es igualmente imprescindible la integración del análisis de la imputabilidad del empleador, así como de las teorías de responsabilidad civil subjetiva y objetiva. Tanto el reproche a la negligencia o culpa en la conducta del empleador, como el análisis de la exterioridad del hecho dentro de la causalidad circunstancial de la ecuación determinativa de dicha causal, permitirá que la imposibilidad absoluta y el cese definitivo establecida en la LOAH tenga una evaluación circunstancial y relativa a cada situación.

La gran mayoría de terminaciones del contrato de trabajo, por la invocación de esta causal, se han atribuido a situaciones de crisis económica. De conformidad con las legislaciones analizadas, y, dado que tal situación no debería tener la calidad de ser fortuita o de fuerza mayor, dichas terminaciones contractuales serán automáticamente intempestivas y por lo mismo, indemnizadas como la Ley establece. Será deber de las autoridades judiciales, considerar todos estos elementos, a fin de que sea la jurisprudencia la cual materialice el desarrollo jurídico de dicha causal en el ordenamiento jurídico ecuatoriano. 